\title{
COMPARAÇÃO DOS MÉTODOS DE IMAGEM NO DIAGNÓSTICO DOS TUMORES RENAIS E CALCIFICAÇÕES NESTAS NEOPLASIAS
}

\author{
Sergio Marrone Ribeiro*, Sergio Aron Ajzen, José Carlos Souza Trindade \\ Trabalho realizado na Faculdade de Medicina da Universidade Federal de São Paulo (UNIFESP), \\ São Paulo, SP e Faculdade de Medicina da Universidade Estadual Paulista \\ "Júlio de Mesquita Filho" (UNESP), Botucatu, SP
}

RESUMO - OBJETIVo. Tentar estabelecer uma metodologia no diagnóstico e conduta dos pacientes com massas renais sólidas e complexas, comparando os custos e benefícios dos diferentes métodos de diagnóstico por imagem. Procuramos avançar no diagnóstico diferencial entre lesões benignas e malignas, particularmente através da investigação das calcificações tumorais.

Métodos: Realizamos um estudo prospectivo em 31 pacientes portadores de massas renais sólidas ou complexas, todos eles submetidos à ultra-sonografia abdominal (US), ultra-sonografia doppler da massa renal (US Dop), tomografia computadorizada (TC) e ressonância magnética (RM).

RESULTADOS. Encontramos 28 pacientes com massas malignas e três com massas benignas. Entre os 28 pacientes com lesões malignas, 17 mostraram calcificações pela TC; 16 deles calcificações do tipo central e um calcificação do tipo curvilinear periférica pura (casca de ovo). A urografia excretora (UGE) mostrou uma taxa de detecção para calcificaçóes significantemente menor que a US e a TC. Massas benignas e malignas apareceram como descrito na literatura, com o US, TC e RM mostrando alta sensibilidade e especificidade no diagnóstico dos tumores renais. A exceção foi na US Dop, onde nós obtivemos menor sensibilidade para a caracterização de fluxo tumoral maligno.

ConCLUsÖEs. Foi surpreendente verificar que a TC revelou calcificações centrais em $\mathbf{5 1 , 6 \%}$ dos pacientes desta série, todas elas em lesões malignas, quando a literatura refere uma freqüência de calcificações entre $8 \%$ e $22 \%$ dos carcinomas de células renais, em estudos utilizando radiografias simples do abdômen e UGE. Este achado é de grande importância quando consideramos que estas calcificaçóes ocorrem particularmente em neoplasias malignas. Como resultado da comparação dos diferentes métodos de diagnóstico por imagem, nós propomos uma metodologia para adequada investigação dos tumores renais.

Unitermos: Neoplasias renais. Diagnóstico por imagem. Estudo comparativo. Tomografia computadorizada. Ultra-som. Ressonância magnética.

\section{INTRODUÇÃO}

O grande desenvolvimento de modernos métodos de diagnóstico por imagem nas últimas décadas trouxe implicações importantes na abordagem dos tumores renais. Além de aumentar a detecção precoce destes tumores, por vezes descobertos incidentalmente, aumentou também a detecção de massas benignas antes não identificadas, com conseqüências diretas na conduta terapêutica. Estas últimas devido às dificuldades na diferenciação de pequenas lesões sólidas benignas das malignas.

Estes novos métodos de diagnóstico por imagem também trouxeram certa confusão quanto ao melhor caminho a seguir na investigação destas massas, diante dos diferentes custos e benefícios destes exames. Os custos envolvem o preço do exame, sua disponi-

\footnotetext{
*Correspondência:

Rua Nelo Pedretti, n. ${ }^{\circ} 420$ - Chácara Barros

CEP: 18609-030 - Botucatu - SP - Brasil

Telefone: (14) 6802-6088

sribeiro@fmb.unesp.br
}

bilidade e invasibilidade, além de riscos como exposição à radiação ionizante e reações alérgicas ao meio de contraste intravenoso. Quanto aos benefícios: a capacidade do método de detectar, de diferenciar lesões presumivelmente benignas das malignas e estadiar acuradamente as lesões malignas.

Com o objetivo de comparar estes diferentes custos e benefícios, realizamos um estudo prospectivo em 3 I pacientes portadores de massas renais sólidas ou complexas submetidos aos exames de urografia excretora (UGE), ultra-sonografia abdominal (US), ultrasonografia doppler da massa renal (US Dop), tomografia computadorizada (TC) e ressonância magnética (RM). Ao final deste estudo, elaboramos um diagrama que consideramos ser o melhor caminho a seguir na investigação destes tumores.

O objetivo inicial deste trabalho era comparar os diferentes métodos de imagem no diagnóstico e estadiamento dos tumores renais, assim como tentar avançar no diagnóstico diferencial das massas sólidas e complexas benignas das malignas. Na questão do diagnóstico, suspeitamos que as calcificações, que ocorrem associadas às neoplasias renais malignas, poderiam facilmente passar despercebidas. Observações prévias quanto ao aspecto destas calcificaçỗes, mais evidente pela tomografia computadorizada, associada à importância da sua detecção pela forte presunção de malignidade da lesão, fizeram com que destacássemos a investigação da acurácia destes métodos na detecção de calcificações tumorais como um segundo objetivo deste trabalho, embora diretamente relacionado ao primeiro.

\section{Métodos}

Foi realizado estudo prospectivo em 37 pacientes portadores de massas sólidas ou complexas, suspeitadas clinicamente ou diagnosticadas pela realização de algum exame de imagem e encaminhados ao nosso serviço. Destes 37 pacientes, seis foram excluídos do estudo ou por não ter um diagnóstico final 
conclusivo ou em função do protocolo ter ficado incompleto, geralmente por recusa do paciente em prosseguir a investigação ou por abandono do tratamento, impossibilitando a análise estatística dos dados.

Dos 31 pacientes estudados, 20 eram do sexo masculino e II do sexo feminino, com idades variando de 31 a 85 anos (idade média de 58,2 anos). Todos os pacientes foram avaliados por meio de ultra-sonografia abdominal (US), ultra-sonografia doppler da massa renal (US Dop), tomografia computadorizada (TC) e ressonância magnética (RM).

A ultra-sonografia abdominal e ultrasonografia doppler da massa renal foram avaliadas por dois radiologistas nos aparelhos ATL (Ultramark 9, USA) e Toshiba (Sonolayer SSHI 40 A/G, Japan). Foi realizada análise espectral do fluxo sangüíneo da massa utilizando um filtro de parede baixo, padronizado em $100 \mathrm{~Hz}$. A amostra de volume foi reduzida após detectar fluxo na massa e a máxima freqüência Doppler de fluxo sistêmico foi anotada, além das medidas da diástole final e do índice de resistividade.

Os exames de tomografia computadorizada foram realizados em aparelhos convencionais marca Siemens (Somatom DRG, Germany); Schimadzu (SCT-4500T, Japan) e General Eletric (CT 9800, USA). Foram realizados cortes de $5 \mathrm{~mm}$ de espessura por $5 \mathrm{~mm}$ de incremento na topografia dos rins na fase sem contraste, e $10 \mathrm{~mm}$ de espessura por 10 $\mathrm{mm}$ de incremento em todo abdômen, até o nível logo abaixo da bifurcação da aorta, quando foram injetados cerca de 120 a $\mid 40$ ml de contraste iodado a $60 \%$. Foi também ministrado contraste via oral para contrastação das alças intestinais.

Os exames de ressonância magnética foram realizados nos aparelhos marca Philips (Gyroscan S-I 5 HP de I,5 Tesla, Neederland) e General Eletric-CGR (MR MAX de 0,5 Tesla, France). Utilizou-se faixa de compressão abdominal e compensador de movimentos respiratórios para minimizar artefatos de movimento. Foram realizados, na topografia dos rins, cortes nas seqüências: "Spin - Echo" (SE) ponderada em TI no plano axial, sem contraste, e no plano coronal após a injeção intravenosa de gadolíneo. Compreendendo todo o abdômen, até a bifurcação da aorta, foram realizadas as seqüências "Spin - Echo" (SE) ponderada em T2 e Densidade de
Protons (DP) e "Spin - Echo"(SE) ponderada em TI no plano axial, após a injeção de I2 a I 5 $\mathrm{ml}$ de contraste intravenoso (gadolineo). Os cortes foram realizados com 5 a $10 \mathrm{~mm}$ de espessura, tanto nos planos coronal como axial. Em função de um dos aparelhos ser de 0.5 T não foi possível a realização de seqüências rápidas, como imagens gradiente echo com o paciente em apnéia durante a injeção dinâmica do gadolínio.

Os exames de diagnóstico por imagem foram analisados detalhadamente tanto em relação aos aspectos do diagnóstico como do estadiamento das lesões, procurando se caracterizar a densidade da massa em relação ao parênquima renal normal, os contornos, dimensões, localização e a presença ou não de calcificações. Quanto à extensão da massa, avaliou-se a presença ou não de invasão da gordura peri-renal, das estruturas adjacentes, da veia renal e veia cava inferior, linfonodomegalias hilares e retroperitoneais. Entretanto, os dados relativos ao estadiamento foram discutidos em outro artigo e não serão aqui apresentados!'

As calcificações foram analisadas pela UGE, US e pela TC quanto à sua presença $\mathrm{e}$ aspecto, sendo classificadas em dois grupos: a) calcificações puntiformes ou granuladas centrais ou ainda curvilineares que se estendem para o interior da massa; b) calcificações do tipo curvilinear periférica pura (sem se estender para o interior da massa), também chamada de calcificação em "casca de ovo"2,3,4, É importante lembrar que calcificações curvilineares periféricas que se estendem para o interior da massa são também fortemente indicativas de malignidade, sendo, portanto, incluídas no grupo das calcificações centrais ${ }^{4}$ (grupo a).

Foram também avaliadas alterações no sistema pielocalicial, efeito expansivo, crescimento exofítico ou aspecto infiltrativo, invasão do seio renal, assim como a presença de outras lesões, associadas ou não à lesão renal, tais como metástases ósseas, hepáticas e ascite.

Os dados foram analisados separadamente por dois médicos radiologistas em protocolo previamente estabelecido, sem o conhecimento dos resultados dos outros exames. Nos casos onde ocorreu discordância dos achados, os exames foram submetidos à análise de um terceiro radiologista, obtendo-se assim um parecer final que foi posteriormente comparado com os achados cirúrgicos e anatomopatológicos.

Para a análise dos resultados foram utilizados testes não paramétricos, levando-se em consideração a natureza das variáveis estudadas. $O$ teste $G$ de COCHRAN ${ }^{5}$ foi utilizado para estudar as diferenças na detecção de calcificações entre a UGE, US e TC. Este é um teste particularmente útil quando se pretende estudar as discordâncias entre os resultados observados, se são ou não significativas. A UGE foi realizada em 25 destes 31 pacientes, e este número foi considerado suficiente para a sua inclusão na análise estatística dos dados. Em todos os testes fixou-se em 0,05 ou 5\% o nível para a rejeição da hipótese de nulidade, assinalando-se com um asterisco os valores significantes.

O presente trabalho foi aprovado pela Comissão de Ética Médica e houve o consentimento dos pacientes para a realização dos exames.

\section{Resultados}

O diagnóstico final revelou que 28 desses pacientes eram portadores de massas malignas e três de lesões benignas. Das 28 massas malignas, 20 eram carcinomas de células renais, três carcinomas de células transicionais e cinco ficaram sem o diagnóstico histopatológico final, pois em três destes pacientes os tumores eram cirurgicamente irressecáveis e os outros dois tinham metástases à distância, contra-indicando a cirurgia. Provavelmente também se tratavam de carcinomas de células renais pelos seus aspectos cirúrgicos e de diagnóstico por imagem, além dos achados clínicos compatíveis. Destes 23 pacientes portadores de massas malignas que realizaram exame histopatológico, o diagnóstico final de 21 deles foi obtido através de cirurgia e exame anatomopatológico, em um caso por biópsia de metástase pulmonar e no outro após cirurgia e exame histopatológico de metástase cerebral, esta última responsável pelas primeiras manifestações clínicas do paciente. As três lesões benignas encontradas eram um hematoma em organização, um mixoma renal e um pseudotumor, as duas primeiras diagnosticadas por cirurgia e exame anatomopatológico e a última comprovada pelo seguimento clínico e radiológico do paciente. 

Figura I - WSB, homem de 56 anos com carcinoma de células transicionais visto na pielografia ascendente (A) como uma falha de enchimento irregular na pelve e sistema coletor adjacente, provocando dilatação dos cálices a montante, também demonstrado pela US (B). A TC pós-contraste (C) e o corte coronal ponderado em TI da RM (D) também demonstram claramente a localização da massa sugerindo o diagnóstico

A

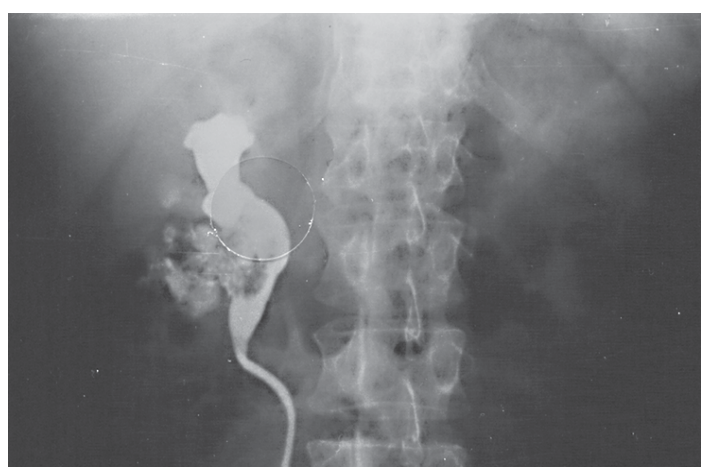

C

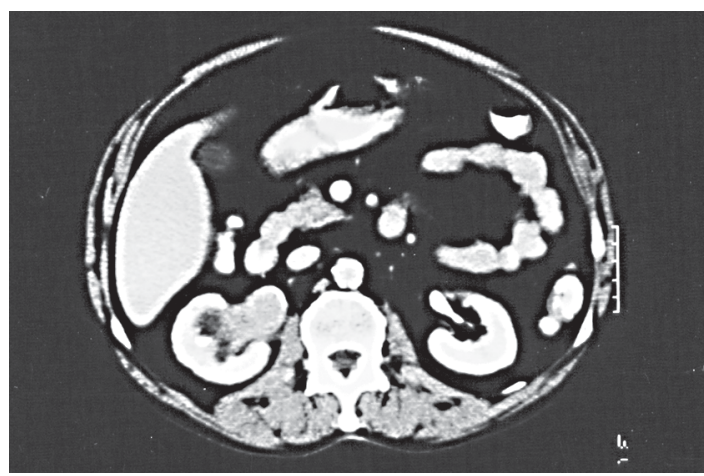

B

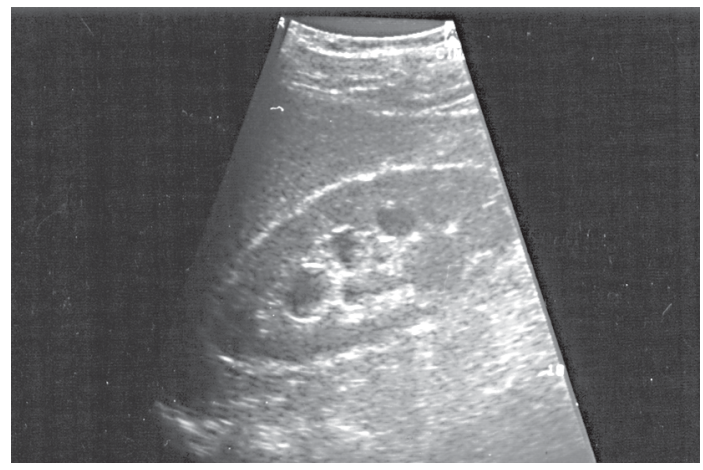

D

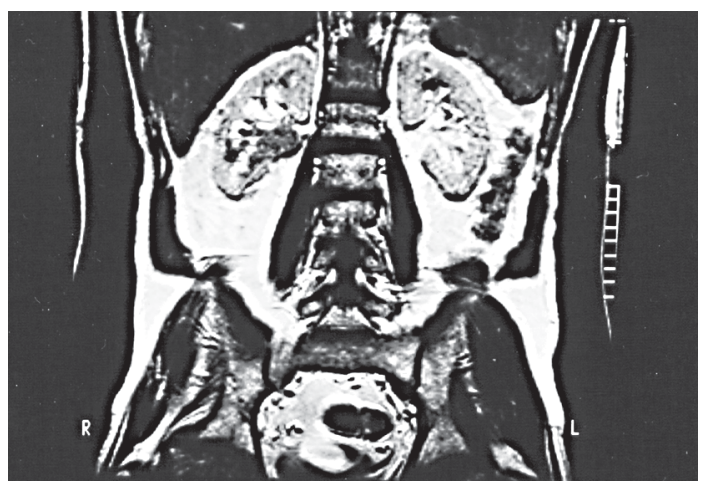

Nas 28 lesões malignas, compostas por carcinomas de células renais e carcinomas de células transicionais, não encontramos diferenças radiológicas significativas entre estas duas neoplasias, a não ser pela localização dos carcinomas de células transicionais. Os três casos de carcinomas de células transicionais localizavam-se no seio renal, ocupando principalmente a pelve, onde provocavam falhas de enchimento com amputação de cálices nos três casos, irregularidade e dilatação localizada do sistema coletor em dois casos, alterações melhor observadas na UGE e pielografia ascendente (Fig. IA). Em dois pacientes estas alterações sugeriam o diagnóstico, porém, em um deles o tumor era grande, com extensa infiltração do parênquima adjacente, principalmente do pólo superior, além da infiltração da cápsula renal, gordura perinéfrica e adrenal, não sendo possível diferenciá-lo de um carcinoma de células renais.

Exceto pela textura homogênea e contorno mais regular observado no menor caso de carcinoma de células transicionais (Figs. IB e IC), características também observadas em um caso de carcinoma de células renais pequeno, todas as lesões malignas apresentaram textura heterogênea na US, TC e RM, contornos irregulares/bosselados, além de realce heterogêneo após a injeção intravenosa do contraste iodado, menor que o do parênquima renal normal adjacente. Dezesseis massas apresentaram imagens de conteúdo líquido em seu interior compatíveis com áreas de necrose, hemorragia ou degeneração cística.

Excluídos os três casos de carcinoma de células transicionais, das outras 25 massas malignas (provavelmente todas carcinomas de células renais), 20 realizaram urografia excretora, observando-se as seguintes alterações no sistema coletor: amputação de grupamentos caliciais em I I casos, exclusão renal em quatro casos, deslocamento ou estiramento em || casos, dilatação localizada em seis casos e irregularidades no sistema pielocalicial em três casos. Estas alterações apareceram nos exames de US, TC e RM como formação expansiva que se estendia para o seio renal, por vezes comprimindo, rechaçando e provocando dilatações localizadas no sistema coletor. Duas pequenas massas, uma com $2,5 \mathrm{~cm}$ e outra com 3,2 cm de diâmetro não foram identificadas pela UGE. Todas as 31 massas foram identificadas pela US, TC e RM.

Das 3 I lesões, 29 se apresentaram como um efeito de massa e somente duas tinham um aspecto infiltrativo, sendo estas duas últimas lesões malignas volumosas que envolviam todo o rim.

Quanto às três massas benignas, o hematoma em organização apresentou-se como uma pequena imagem arredondada de contornos regulares e de textura heterogênea na US (Fig. 2A) e TC, isoecogênica e hipodensa respectivamente, e com um hipossinal homogêneo em TI e T2 na RM(Fig. 2B), porém com uma faixa de hipersinal em T2. Em um segundo exame de TC, esta lesão se apresentou com uma hiperdensidade sugestiva de hemorragia recente (Fig. 2C).

mixoma renal, neoplasia benigna muito rara, apareceu como uma volumosa massa 
Figura 2 - WSG, mulher de 52 anos com um hematoma visto na US (A) como uma massa isoecóica ao parênquima renal que determinava reforço acústico posterior. (B) A RM ponderada em T2 mostra imagem arredondada hipointensa com área de hipersinal no seu interior. Nesta TC pré-contraste $(\mathrm{C})$ a lesão apareceu hiperdensa, sugerindo o diagnóstico de hemorragia recente

A

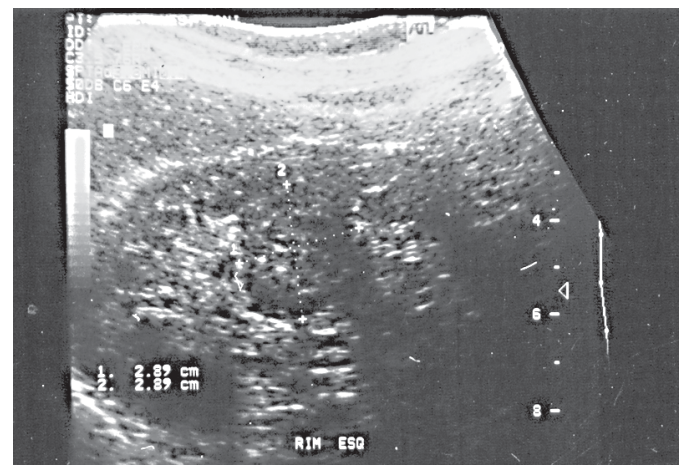

B

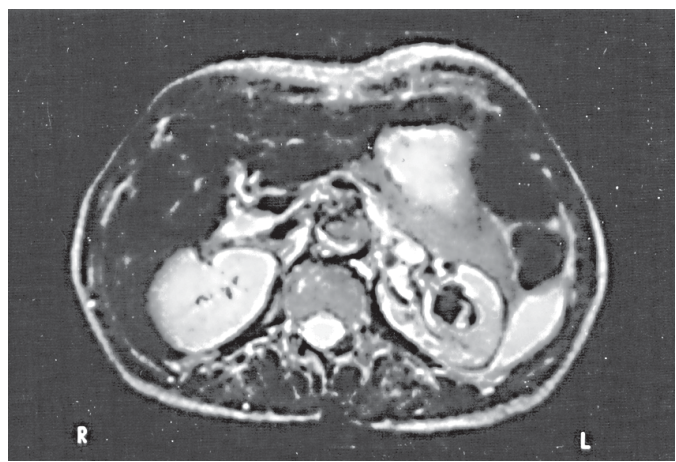

C

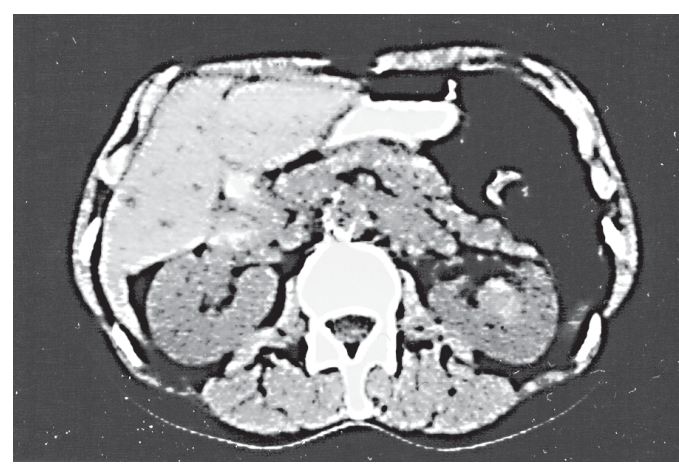

heterogênea, predominantemente hiperecóica na US e hipodensa na TC, e com sinal mais homogêneo na RM, onde se apresentava com hipossinal em $\mathrm{T}$ I e hipersinal em T2. Seus contornos eram relativamente regulares, com discretas bosseladuras, e sua interface bem definida junto ao parênquima renal adjacente, somente deslocando as estruturas, sem invadi-las.

O pseudotumor se apresentou como uma pequena imagem nodular periférica homogênea e de contornos regulares, caprichosamente formada por uma retração cicatricial arredondada, que delimitava um de seus contornos e que foi melhor definida pela TC e RM. A lesão tinha a mesma densidade que o parênquima renal em todos os exames e se realçou homogeneamente pelo contraste intravenoso, igual ao parênquima renal adjacente.

Somente um paciente apresentou calcificação periférica pura. Tratava-se de uma calcificação pequena em um paciente portador de carcinoma de células renais (Fig. 3A). Todas as demais calcificações foram classificadas como do tipo central (Fig.3), sendo identificadas em oito pacientes pela UGE, 13 pela US e 14 pela TC, considerando-se somente os 25 pacientes que realizaram estes três exames. $O$ teste G de COCHRAN mostrou discordância significante entre os métodos de diagnóstico por imagem no que diz respeito à detecção de calcificação central. Mostrou que a UGE apresentou uma capacidade de detecção significantemente menor do que a US e a TC, os quais não diferiram entre si (Tabela I). Nos outros seis pacientes que realizaram somente US e TC, foram identificados mais dois pacientes com calcificações centrais por estes métodos, perfazendo um total de 16 pacientes com calcificação central pela TC. Destes, um tinha carcinoma de células transicionais (caso 27 - Tabela 2), I I tinham carcinomas de células renais e quatro ficaram sem diagnóstico anatomopatológico final, dos quais três foram irressecáveis (casos 4, 7 e 26) e um se encontrava em estádio IV-B, não sendo submetido à cirurgia (caso 20). aspecto cirúrgico destes tumores irressecáveis, relatado pelos urologistas, era de carcinoma de células renais. No entanto, excluindo estes casos sem diagnóstico anatomopatológico confirmatório, temos I I casos de calcificação central, num total de 20 pacientes com carcinoma de células renais (55\%).

As medidas das freqüências Doppler de pico sistólico obtidas nas massas renais dos 3 I pacientes estudados são mostradas na Tabela 2. Destes, oito pacientes apresentavam freqüência doppler de pico sistólico no tumor renal maior ou igual a 2,5 $\mathrm{kHz}$, sendo que seis tiveram diagnóstico confirmado de carcinoma de células renais, um de carcinoma de células transicionais e um ocorreu num dos tumores malignos irressecáveis.

A impressão diagnóstica dos radiologistas, feita de forma independente para cada exame realizado, é apresentada na Tabela 2 juntamente com o resultado cirúrgico e anatomopatológico final. Evitou-se, na medida do possível, classificar lesões com o diagnóstico de inconclusivo. 
Figura 3 - TC pré-contraste de pacientes com carcinoma de células renais mostrando calcificação curvilinear periférica (A) e pequenas calcificaçóes de aspecto puntiforme ou mosqueado localizadas no interior do tumor $(B, C \in D)$

A

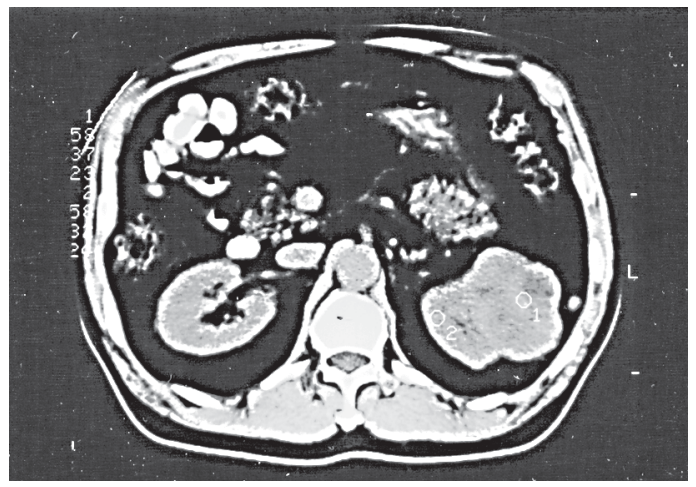

C

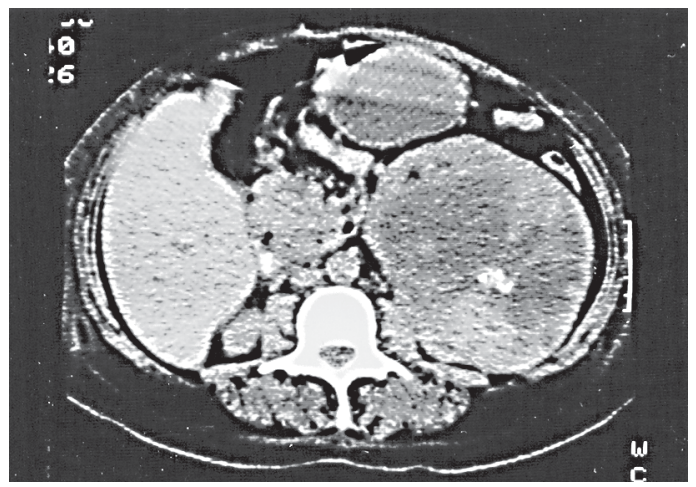

B

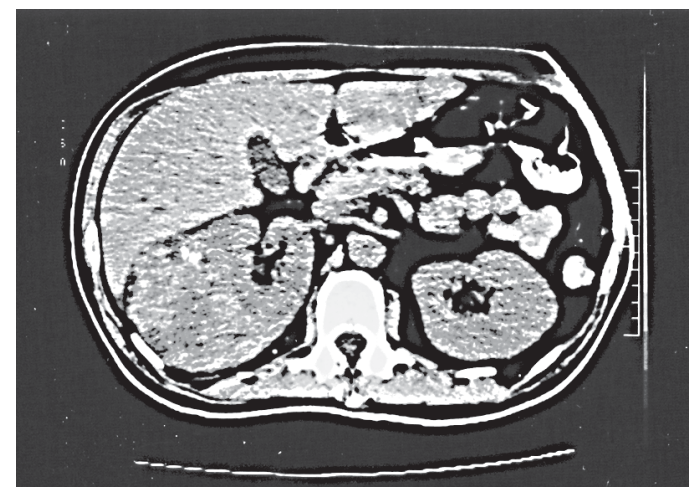

D

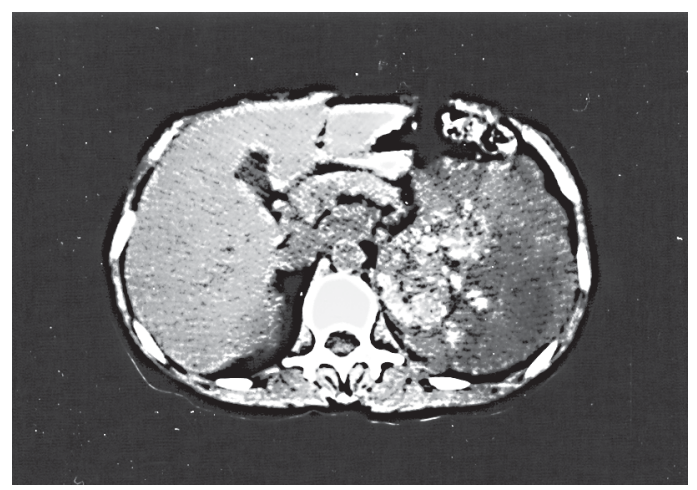

\section{Discussão}

Os achados clínicos e epidemiológicos apresentaram boa concordância com os descritos na literatura, mostrando que o carcinoma de células renais é aproximadamente duas vezes mais freqüente em homens que em mulheres e que a sua incidência aumenta com a idade, sendo mais comum entre os 50 e 70 anos. Hematúria e dor foram os sintomas mais freqüentes, seguidos de anemia, emagrecimento e massa palpável. Houve pacientes sem qualquer sintoma do trato urinário ou em que os primeiros sintomas se deveram à metástase, comportamentos atípicos que o caracterizam como "tumor fantasma", sendo um dos grandes mimetizadores em medicina ${ }^{6}$.

Duas lesões pequenas, uma com $2,5 \mathrm{~cm}$ e outra com 3,2 cm em seus maiores diâmetros, não foram detectadas pela UGE. Mesmo associada à planigrafia, a UGE falha com freqüência nos tumores pequenos ${ }^{7,8}$. Vários autores têm mostrado a baixa sensibilidade da UGE nas lesões pequenas quando comparada a outros métodos ${ }^{9,10}$, com alta taxa de falsos-negativos, e até massas grandes não detectadas têm sido descritas $7,8,11-13$. Os tumores renais de crescimento infiltrativo, menos comuns que os de crescimento expansivo, também são de difícil avaliação pela UGE, especialmente na fase mais precoce da doença, em que o tamanho, contornos e cálices renais são normais. De forma diferente, a TC e a US são valiosas no reconhecimento deste tipo de crescimento ${ }^{14,9}$. Existem importantes limitações na caracterização das massas pela UGE, detectadas por sinais indiretos e não pela visualização direta do tumor. Assim, para a diferenciação das neoplasias de outros processos patológicos a UGE tem um papel até menor que na detecção destas lesões ${ }^{8}$. Isto também faz com que este exame aumente os riscos e custos dos procedimentos diagnósticos sem aumentar a acurácia ${ }^{11,15,13}$ e sem excluir uma massa renal maligna suspeitada clinicamente ${ }^{7}$.

Apesar da sua sensibilidade não ser a ideal, a UGE é freqüentemente o primeiro exame a chegar às mãos do radiologista na investigação de hematúria e dor lombar. A planigrafia é essencial para aumentar sua sensibilidade e especificidade, sem a qual pequenas massas passam facilmente despercebidas ${ }^{16}$. Cortes planigráficos antes da injeção do contraste são de grande ajuda para melhor definição e detecção de pequenos cálculos ou de calcificações renais. No presente trabalho, a UGE foi também um importante ponto de comparação com estudos anteriores na avaliação das calcificações, já que a radiografia simples do abdômen ou os cortes planigráficos antes da injeção intravenosa do contraste podem mostrar calcificações centrais, por si só suficientes para o diagnóstico de uma neoplasia renal maligna².

Fica claro, assim, que apesar da UGE não estar indicada na suspeita de massa renal, tanto ela quanto a radiografia simples do abdômen podem fornecer importantes informações naqueles pacientes com hematúria e dor lombar. Apesar destes sintomas indicarem a realização 
Tabela I - Pacientes com tumores renais, segundo a presença( + ) ou ausência (-) de calcificação central*, detectada pela urografia excretora (UGE), ultra-sonografia (US) e tomografia computadorizada (TC)

\begin{tabular}{ccccc}
\hline$N^{0}$ & Paciente & UGE & US & TC \\
1 & 1 & - & - & - \\
2 & 2 & + & - & + \\
3 & 3 & - & - & - \\
4 & 4 & - & + & + \\
5 & 6 & + & + & + \\
6 & 7 & + & + & + \\
7 & 8 & - & + & + \\
8 & 9 & - & - & - \\
9 & 10 & - & - & - \\
10 & 12 & + & + & - \\
11 & 13 & + & + & + \\
12 & 14 & - & - & + \\
13 & 16 & - & + & + \\
14 & 17 & - & - & - \\
15 & 18 & - & + & + \\
16 & 19 & - & - & + \\
17 & 20 & + & + & - \\
18 & 21 & + & + & + \\
19 & 22 & - & - & - \\
20 & 23 & - & + & + \\
21 & 24 & - & + & + \\
22 & 26 & - & - & - \\
23 & 27 & - & - & - \\
24 & 29 & 52,0 & 56,0 \\
25 & 31 & & + & + \\
\hline Total & & & + & + \\
$\%$ & & - & + & + \\
\hline
\end{tabular}

* Calcificaçôes com aspecto altamente sugestivo de malignidade, definidas como calcificaçôes puntiformes ou mosqueadas centrais ou curvilinear que se estende para o interior da massa. Excluída calcificação curvilinear periférica pura (casca de ovo).

Teste $G$ de COCHRAN

$G$ calculado $=7,75^{*} \quad G$ crítico $=5,99$

da UGE devido a outras causas muito mais freqüentes do que as neoplasias renais, eles compõem, juntamente com a presença de massa palpável, a clássica tríade clínica do carcinoma renal, vista em somente $4 \%$ a $9 \%$ dos pacientes nas grandes séries estudadas ${ }^{17,18,6}$.

Na nossa casuística, as massas de todos os 3I pacientes foram detectadas pela US, TC e RM. Apesar de estudos iniciais terem mostrado que a US era um método limitado na detecção de lesões menores que $2 \mathrm{~cm}$, particularmente em tumores isoecogênicos de localização difícil, apresentando uma menor acurácia em relação à TC, nas mãos de radiologistas experientes ela se mostrou um método muito sensível, auxiliando na caracterização das lesões renais, particularmente na distinção de massas renais císticas das sólidas $10,8,15,19$. Com os modernos equipamentos de alta resolução e a utilização de uma técnica meticulosa, até pequenas massas renais medindo de 1,3 a $2 \mathrm{~cm}$ de diâmetro podem ser caracterizadas acuradamente pela US20,19. A obesidade e gases intestinais podem diminuir a acurácia da US que é um método operador dependente. A US, também tem grande importância na caracterização adicional de massas renais detectadas por outros estudos, podendo ocasionalmente definir a natureza de uma lesão indeterminada pela TC. Isto é particularmente valioso na pesquisa de massas renais homogêneas com densidade maior do que a água, onde a US pode distinguir massas sólidas de cistos hemorrágicos 21,22 .

Palko et al., em 1990'3, observaram somente pequena diferença entre a acurácia da US, TC e Angiografia na detecção de massas renais. A importância da US está enfatizada pela alta taxa de lesões descobertas acidentalmente, muitas delas não identificadas antes pelo uso somente da UGE, incluindo muitas lesões malignas $(21,6 \%)$. Este fato, associado ao seu baixo custo e risco, faz com que vários autores defendam que a US deva ser realizada durante "check up" médico de rotina com o objetivo de descobrir precocemente tumores renais assintomáticos ${ }^{15,12,13}$. Se um resultado ultrassonográfico negativo para massa renal é clinicamente aceitável, nenhum exame mais é necessário. Porém, se a suspeita de massa renal é alta, a TC está indicada devido à sua maior sensibilidade na detecção de lesões pequenas. A TC também está indicada se o resultado da US for incerto, o que se dá particularmente nas lesões complexas, cistos calcificados e tumores císticos (casos em que a US não preenche todos os critérios para cisto simples) e principalmente quando a US mostra massa sólida, provavelmente maligna ${ }^{13}$. A combinação da US com a TC quase sempre leva a um diagnóstico definitivo na diferenciação de massas sólidas das císticas. Se for encontrada massa cística complexa no exame ultrassonográfico e com aspecto indeterminado pela TC, a investigação deverá prosseguir, sendo a principal preocupação clínica neste caso a necessidade ou não de exploração cirúrgica, e qualquer investigação subseqüente deve ser direcionada para esta questão $0^{23}$. Neste sentido, a classificação das massas císticas de Bosniak é muito importante por separar as lesões provavelmente benignas (categorias I e 2) daquelas que necessitam de cirurgia (categorias 3 e 4$)^{24}$. A acurácia desta classificação em separar as lesões benignas das malignas tem sido estudada por vários autores, cujos achados foram comparados por Koga et al. ${ }^{25}$, que mostraram que a probabilidade de malignidade é de $2 \%$ para as lesões categoria I (cistos simples), 27\% na categoria II (cistos minimamente complicados), 60\% na categoria III (septos maiores que I mm, irregulares e espessamento nodular no sítio de aderência septal) e $90 \%$ na categoria IV (tumores claramente necróticos).

A TC é o método mais sensível e específico, sendo o melhor método de imagem para a detecção de pequenos tumores renais. Diferencia a grande maioria dos cânceres de forma definitiva e é capaz de detectar quantidades muito pequenas de gordura, excluindo o carcinoma de células renais ${ }^{10,8,13,19}$. A TC também substitui bem exames com radioisótopos nos casos onde a UGE e a US deixam dúvida se realmente existe 


\begin{tabular}{|c|c|c|c|c|c|c|}
\hline Paciente & UGE & US & US Dop & TC & RM & Achados cirúrgicos e AP \\
\hline$\overline{1}$ & $\bar{M}$ & $\bar{M}$ & $\frac{1(1.5)}{1.5}$ & $\bar{M}$ & $\bar{M}$ & M-Carcinoma de células renais \\
\hline 2 & M & M & $M(3.3)$ & M & M & M-Carcinoma de células renais \\
\hline 3 & M & M & $M(3.0)$ & M & M & M-Carcinoma de células renais \\
\hline 4 & M & M & $i(-)$ & M & M & M-Tumor irressecável, sem diagnóstico AP \\
\hline 5 & - & M & $1(-)$ & M & M & M-Carcinoma de células renais \\
\hline 6 & M & M & $M(4.1)$ & M & M & M-Carcinoma de células renais \\
\hline 7 & M & M & $1(-)$ & M & M & M-Tumor irressecável, sem diagnóstico AP \\
\hline 8 & I & M & $1(-)$ & 1 & I & M-Carcinoma de células renais \\
\hline 9 & M & M & $M(2.5)$ & M & M & M-Carcinoma de células transicionais \\
\hline 10 & B & 1 & $1(0.7)$ & | & 1 & M-Carcinoma de células renais \\
\hline$\|$ & - & M & $1(0.5)$ & M & M & M-Carcinoma de células renais \\
\hline 12 & M & M & $M(3.3)$ & M & M & M-Carcinoma de células renais \\
\hline 13 & M & M & $\mid(1.4)$ & M & M & M-Carcinoma de células renais \\
\hline 14 & I & M & $1(1.8)$ & M & M & M-Carcinoma de células renais \\
\hline 15 & - & I & $1(-)$ & | & 1 & B-Hematomaemorganizacãa \\
\hline 16 & M & M & $(-)$ & M & M & M-Carcinoma de células transicionais \\
\hline 17 & M & M & $1(0.5)$ & M & M & M-Carcinoma de células renais \\
\hline 18 & M & M & $(1.2)$ & M & M & M-Carcinoma de células renais \\
\hline 19 & M & M & $M(2.7)$ & M & M & M-Carcinoma de células renais \\
\hline 20 & M & M & $\mid(1.3)$ & M & M & M-Tumor estadio IV-B, sem diagnóstico AP \\
\hline 21 & M & M & $1(-)$ & M & M & M-Tumor estadio IV-B, sem diagnóstico AP \\
\hline 22 & M & M & () (1.3) & M & M & M-Carcinoma de células renais \\
\hline 23 & M & M & $1(1.8)$ & M & M & M-Carcinoma de células renais \\
\hline 24 & M & M & $M(5.0)$ & M & M & M-Carcinoma de células renais \\
\hline 25 & - & M & $1(-)$ & M & M & M-Carcinoma de células renais \\
\hline 26 & M & M & $M(6.8)$ & M & M & M-Tumor irressecável, sem diagnóstico AP \\
\hline 27 & M & M & $1(-)$ & M & M & M-Carcinoma de células transicionais \\
\hline 28 & - & M & $1(-)$ & M & M & M-Carcinoma de células renais \\
\hline 29 & M & M & $(1.4)$ & M & B & B-Mixoma renal \\
\hline 30 & - & M & $1(2.0)$ & M & M & M-Carcinoma de células renais \\
\hline 31 & B & $B$ & $1(-)$ & B & B & B-Pseudotumor \\
\hline
\end{tabular}

${ }^{*}$ Casos assinalados com hífen (-) correspondem àqueles onde não foi realizada UGE e casos com I(-) correspondem àqueles nos quais nenhuma frequêencia arterial foi detectada na massa.

massa ou se estamos diante apenas de uma variação anatômica/pseudotumores.

O uso da US e da TC suplantou a utilização da angiografia no diagnóstico e estadiamento dos tumores renais, restando-lhe algumas indicações específicas e limitadas como mapeamento da vascularização renal antes de cirurgias conservadoras do parênquima e na embolização pré-operatória. A TC provou ser um método melhor tanto no diagnóstico como no estadiamento, sendo também menos invasiva, mais rápida e menos dispendio$\mathrm{sa}^{21,26,16,13}$. O advento da tomografia computadorizada helicoidal (TCH) tem possibilitado o mapeamento arterial renal de forma tão acurada quanto a arteriografia, e ainda mais acurada para a anatomia venosa ${ }^{27}$. A TC tridimensional fornece ao cirurgião uma forma única de visualizar a anatomia renal de modo semelhante àquele visto ordinariamente na cirurgia. Possibilita ainda a realização de uma nefroscopia virtual no estudo das neoplasias das vias excretoras, classificando melhor os tipos de lesões: séssil, pedunculada, infiltrante, ulcerada, etc., correlacionando-as melhor com o exame anatomopatológico ${ }^{28}$.

Apesar da RM detectar todas as massas, foram evidentes as dificuldades na definição de muitas delas por apresentarem sinal semelhante ao do parênquima renal adjacente, além dos artefatos de movimento que prejudicaram muito a resolução da imagem. A alta sensibilidade da RM nesta série provavelmente se deveu também ao fato da maioria das lesões ser grande e heterogênea, com alterações nos contornos, invasão do seio renal e necrose central. De forma geral, as lesões foram identificadas muito mais facilmente pela $\mathrm{TC}$.

A maioria dos autores concorda que a TC dinâmica com contraste ainda é o exame de escolha para detecção de pequenas lesões renais. É o exame de imagem preferido para o diagnóstico e estadiamento, também por ser mais barato e mais largamente acessível que a RM. A vantagem mais significativa da RM é a sua capacidade de melhorar o estadiamento do carcinoma de células renais ou complementar a TC para o estadiamento, além de ser uma alternativa nos casos onde existem contraindicações ao contraste iodado na TC20,29,30.

Uma outra desvantagem da RM em relação à TC no diagnóstico das massas renais é a incapacidade da RM de detectar calcificações, que se manifestam com ausência de sinal em todas as seqüências. A TC, ao contrário, é muito sensível na detecção e caracterização das calcificações, tornando-se muito útil na definição das lesões malignas, principalmente quando as calcificações são do tipo central.

Foi surpreendente observar nesta série que a calcificação central foi identificada em $32 \%$ dos pacientes pela UGE, 48,2\% dos pacientes pela US e em $51,6 \%$ dos pacientes pela TC. Se considerarmos somente os pacientes portadores de carcinoma de células renais, estas freqüências sobem ainda mais, sendo muito elevadas quando comparadas com os dados da literatura, que relatam freqüência de calcificação nos carcinomas de células renais entre $8 \%$ e $22 \% \%^{31,2-4}$. Estas freqüências, porém, foram observadas em estudos realizados somente com radiografias simples do abdômen e UGE. Nenhum dos levantamentos foi feito utilizando-se a TC. Mesmo assim, a freqüência encontrada em nossos pacientes utilizando somente radiografias simples do abdômen e UGE foi superior aos valores mais altos referidos na literatura. É importante dizer que as calcificações que ocorrem nos tumores renais são pequenas e pouco densas, sendo de difícil identificação nas radiografias. É por vezes difícil determinar se estas imagens são realmente de densidade cálcica e não de densidade de partes moles, como pode parecer o conteúdo de alças intestinais com somações de imagens radiológicas, tornandose tarefa difícil caracterizá-las como alteração patológica ou ainda distingui-las de pequenos cálculos. Provavelmente a alta sensibilidade para a sua detecção nas urografias excretoras 
Ribeiro SM Et AL.

desta série se deveu ao fato dos radiologistas que analisaram estes exames estarem à procura destas calcificações patológicas, pois sabiam previamente que poderiam surgir como densidades muito tênues, e que o protocolo era de tumores renais. Sob este aspecto, a tomografia computadorizada se mostrou muito superior, pois o contraste aqui presente entre as calcificações e demais estruturas é muito grande e, mesmo sendo muito pequenas, passam a ser identificadas, além de serem precisamente localizadas, diferenciando-as de cálculos que se situam no seio renal (Fig. 3).

Weiman et al. ${ }^{4}$ referem que a TC, além de ser um método muito sensível na detecção das calcificações, define mais precisamente do que qualquer outro método de diagnóstico por imagem tanto o seu aspecto como a sua localização exata, se central, periférica ou em ambas as regiões. Assim, a TC caracteriza de forma muito mais acurada que a Radiografia simples e a UGE a natureza benigna, maligna ou indeterminada de uma lesão, também por definir melhor seu conteúdo: se líquido, sólido ou complexo 4 .

A US, apesar de mostrar boa sensibilidade na detecção dessas calcificações, apresenta dificuldades na sua caracterização. A forte sombra acústica, se por um lado facilita a detecção destas calcificações, por outro dificulta a sua caracterização de forma mais detaIhada, e pode obliterar o conteúdo da lesão no caso de calcificações periféricas.

As calcificaçỗes centrais, que nos indicam com tão elevada acurácia a natureza maligna dos tumores, existem em uma freqüência muito maior do que antes determinado e só não eram identificadas tão freqüentemente porque a radiografia simples e UGE não são bons métodos para identificá-las. Nesta série, a sensibilidade de detecção destas calcificações foi ainda mais elevada porque, no intuito de identificá-las, estabelecemos um protocolo na TC de cortes com a metade da espessura e incremento realizados habitualmente, ou seja, cortes de $5 \mathrm{~mm}$ de espessura por $5 \mathrm{~mm}$ de incremento somente sobre os rins na fase pré-contraste. Se tivéssemos utilizado cortes de $10 \mathrm{~mm}$ de espessura por $10 \mathrm{~mm}$ de incremento, provavelmente muitas destas pequenas calcificações não seriam identificadas. Atualmente, os aparelhos de tomografia computadorizada Helicoidal fazem aquisição volumétrica das imagens, com espessura de corte e incremento menores, tornando mais sensivel a detecção destas pequenas calcificações. Preconizamos assim a realização de cortes finos (5 por $5 \mathrm{~mm}$ ou menos) somente sobre os rins na fase pré-contraste nos casos dos tumores pequenos, onde o diagnóstico diferencial com tumores benignos é mais diff'cil. Nas massas volumosas, tanto o tamanho quanto outros aspectos como áreas de necrose central, irregularidade dos contornos, invasão vascular e de estruturas adjacentes, linfonodomegalias e metástases são aspectos altamente sugestivos de malignidade. Nos casos onde uma ultra-sonografia prévia já tenha demonstrado uma massa grande com características malignas, não haveria a necessidade destes cortes finos na fase pré-contraste.

Apesar de algumas vezes estas pequenas calcificações aparecerem agrupadas, facilitando a sua identificação (Fig.3D), na maioria dos casos elas têm sido identificadas de forma isolada ou em pequenos grupos. Nos casos deste estudo, o tamanho de cada uma destas calcificações isoladas variou de 1 a $6 \mathrm{~mm}$ em seus maiores diâmetros, medidas estas menores que a espessura e incremento utilizados usualmente na fase pré-contraste.

Somente um dos 31 pacientes apresentou calcificação do tipo curvilinear periférica pura ou em "casca de ovo", localizada em um carcinoma de células renais (Fig. 3A). Este achado se correlaciona com o descrito na literatura de que este tipo de calcificação deve ser classificada como indeterminada quanto à benignidade ou malignidade da lesão, uma vez que está mais freqüentemente associada a lesões benignas como cistos complicados e aneurisma de artéria renal, mas em 20\% dos casos ocorre em lesões malignas ${ }^{2,3}$.

Nenhuma das três lesões benignas desta série apresentou qualquer tipo de calcificação.

Quanto ao diagnóstico diferencial das lesões benignas das malignas, foi realizado um diagnóstico presuntivo correto pela US, TC e RM em aproximadamente $90 \%$ dos casos (Tabela 2). 0 caso do pequeno hematoma localizado no seio renal $\left(n^{\circ} \mid 5\right)$ ficou com o diagnóstico inconclusivo pelos três métodos. Dois casos de carcinoma de células renais pequenos ( $n^{\circ} \mathrm{s} 8$ e 10 ) também ficaram com diagnóstico inconclusivo pela TC e RM, um dos quais também pela US $\left(n^{\circ}\right.$ 10). Aqui se encontra a maior dificuldade, estabelecer se pequenas lesões sólidas são benignas ou malignas, particularmente quando são menores que $3 \mathrm{~cm}$. Elas normalmente têm densidade homogênea e contornos regulares, e o realce pelo contraste, que seria um indicativo de malignidade, nem sempre está presente ${ }^{32,10}$. A realização de cortes tomográficos mais finos pode ajudar se calcificações estiverem presentes e mesmo para determinar melhor o aspecto da lesão e do realce após o contraste. Curry, em $1995^{20}$, sugere a repetição da TC com a realização de cortes mais finos antes e após a injeção do contraste em massas renais de 1,5 a 3,0 cm de diâmetro que apresentem coeficiente de atenuação maior do que $20 \mathrm{HU}$. Se a lesão apresentar realce após a injeção IV do meio de contraste, requererá tratamento cirúrgico ${ }^{20}$.

Nos casos de massas sólidas pequenas, sem realce pelo contraste definido e sem calcificações, a conduta não será necessariamente uma nefrectomia radical. Alguns autores defendem cirurgia conservadora ${ }^{33}$, e outros ainda defendem a observação do crescimento ou não destas pequenas massas em exames seriados ${ }^{34}$, uma vez que a incidência de neoplasias mesenquimais benignas aumenta muito no caso das lesões pequenas ${ }^{35}$. Daí a importância da descoberta de discretas calcificações centrais, por indicarem a necessidade de exploração cirúrgica pela sua forte associação com malignidade.

A US Doppler também pode ser útil ao detectar freqüências de fluxo sistólico superiores a 2,5 KHz definindo o diagnóstico de malignidade. Isto aconteceu em um dos casos de carcinoma de células renais pequeno desta série, onde todos os demais exames foram inconclusivos. Infelizmente, a maioria dos casos ficou com diagnóstico inconclusivo pela US Dop, provavelmente devido a dificuldades técnicas que prejudicaram uma melhor avaliação deste método. Entre estas, devemos considerar a curva de aprendizado e que houve uma preocupação no início do trabalho em se detectar estes fluxos anormais no interior da massa, e não na sua periferia, como posteriormente se verificou ser o local correto de sua avaliação. Houve muita dificuldade na detecção destes fluxos em pequenos vasos tumorais, só identificados pela cor, em pacientes idosos e por vezes debilitados, com dificuldade de se manter em apnéia. Um outro aspecto importante, que com certeza influiu na sensibilidade que obtivemos com o método, foi o fato do exame de US Doppler ter sido realizado como uma complementação da US abdominal, 
e não como um exame independente. Sempre que diante de um tumor renal, o ultrasonografista deveria fazer um esforço para estadiar a lesão, procurando avaliar cuidadosamente a veia renal, veia cava inferior e o retroperitôneo, mas não realizar a US Doppler, como foi feito logo em seqüência nesta série. Este deveria ser indicado como um segundo exame complementar independente, onde o ultra-sonografista procurará pesquisar somente a presença ou não de fluxo compatível com malignidade, o que é geralmente muito mais trabalhoso que o exame anterior completo para o diagnóstico e estadiamento. Caso contrário, inevitavelmente, o examinador se sentirá perdendo muito tempo com um único paciente e não terá a necessária paciência para realizar este segundo exame com o devido cuidado. Acredito que a realização desta avaliação como um segundo exame não deva alterar o seu custo, já que a rigor serão sempre dois exames, realizados na seqüência ou não. Outros autores, entretanto, têm obtido bons resultados com a US Doppler, detectando freqüências anormais de pico sistólico maior ou igual a 2,5 kHz em $77 \%$ a $83 \%$ dos carcinomas de células renais ${ }^{36,37,38}$. Entendemos que este exame está sempre indicado e deva ser solicitado antes de procedimentos mais invasivos como a biópsia aspirativa e arteriografia num esforço pré-cirúrgico de se tentar estabelecer a natureza benigna ou maligna de uma lesão indeterminada.

Concluímos com este estudo que foi possivel avançar no diagnóstico diferencial das massas sólidas e complexas benignas das malignas. As calcificações altamente sugestivas de malignidade eram tidas como um achado improvável, identificadas em somente $8 \%$ a $22 \%$ dos carcinomas de células renais. Ao provarmos que elas são muito mais freqüentes, ocorrendo em cerca de metade das neoplasias renais malignas, temos um forte indicativo tanto para a necessidade da conduta cirúrgica nestes pacientes, como um importante delimitador em relação à outra metade destes pacientes sem calcificações, onde as lesões pequenas permanecem geralmente indeterminadas.

Finalmente, com a experiência adquirida neste estudo, sugerimos a seguinte linha de investigação para o diagnóstico e estadiamento das massas renais.

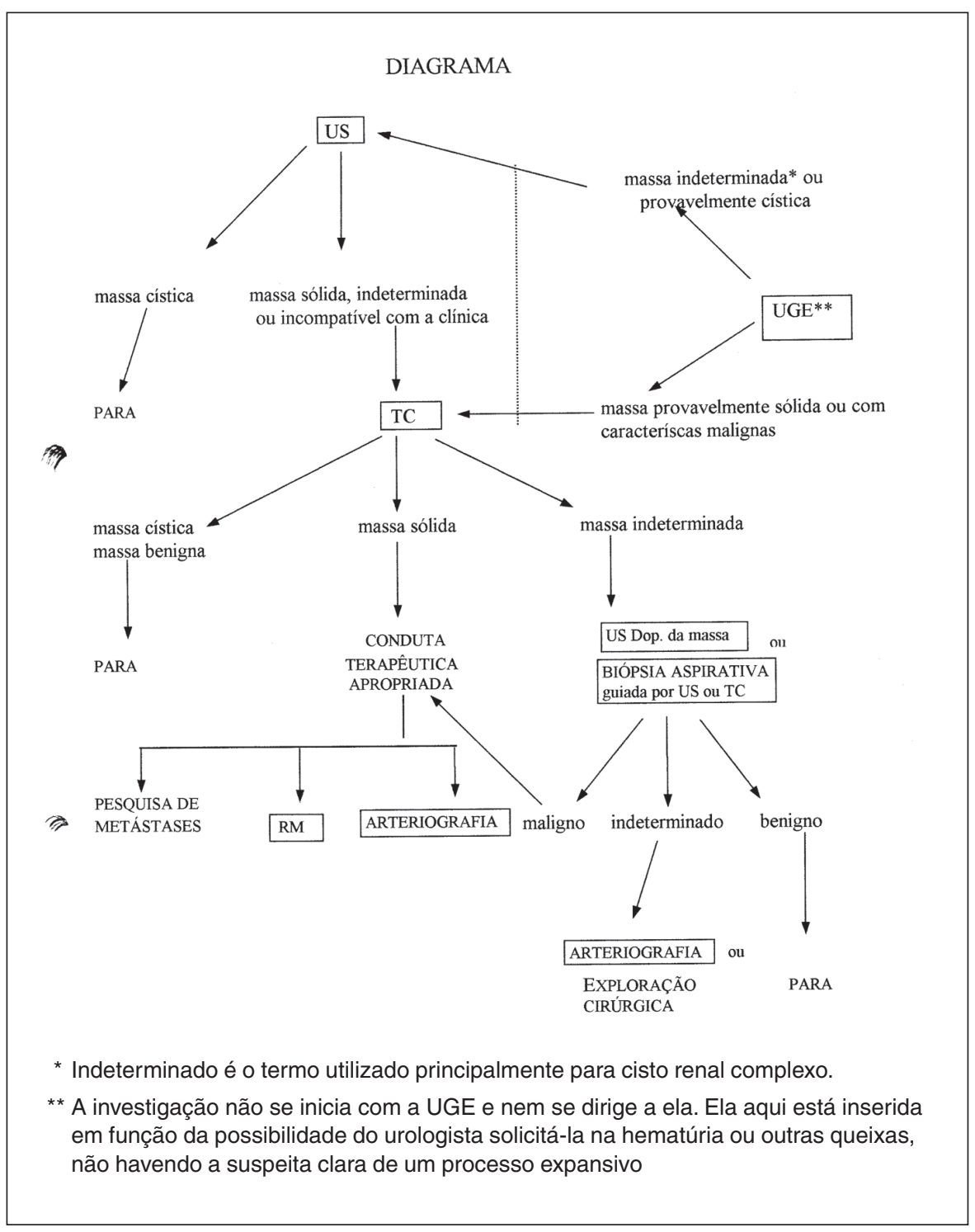

\section{Agradecimento}

Agradecemos a colaboração do Dr. Dejaldo Marcos de Jesus Christofalo na análise dos exames.

Conflito de interesse: não há.

\section{SUMMARY}

COMPARISON OF IMAGING METHODS FOR DIAGNOSIS OF RENAL TUMORS AND THEIR CALCIFICATIONS

BACKGROUND. To establish the bestmethodology for diagnosis and management of patients with solid and complex renal masses by comparing the costs and benefits of different imaging methods and to improve differential diagnosis of these benign and malignant lesions, particularly by investigating tumour calcifications.

METHODS. We performed a prospectivestudy on 3 I patients with solid or complex masses by submitting them to Abdomina/U/trasonography (US), Doppler Ultrasonography of the renalmass (US Dop), Computed Tomography (CT), and Magnetic Resonance Imaging (MRI).

RESULTS. We found 28 patients with malignant and three with benign masses. Of the 28 malignant, 17 showed calcifications at CT; 16 central and one was of the pure peripheral curvilineartype (eggshell). Excretory Urography (IVP) had a significantly lower detection rate for central calcifications than both US and CT. Benign and malignant masses appeared as 
RiBeiro SM ET AL.

described in literature, with US, CT and MRI showing high sensitivity and specificity in renal tumor diagnosis. The exception was US Dop where we obtained lower sensitivity for the characterization of malignant tumor flow.

CONCLUSIONS. In this series we were surprised to find that CT revealed central calcifications in $51.6 \%$ of patients, all with malignant lesions, while, literature reports a frequency of calcification in renal cell carcinoma between 8 and $22 \%$, in studies using abdominal films and EU (IVP). This finding is of great importance when we consider that these calcifications occur particularly in malignant neoplasms. As a result of comparing these different imaging methods we have developed a better methodology for renal tumor investigation. [Rev Assoc Med Bras 2004; 50(4): 403-12]

KEY wORDS: Kidney neoplasms. Comparison studies. Computed Tomography (CT). Magnetic Resonance (MRI). Ultrasound (US). Excretory Urography (IVP).

\section{REFERÊNCIAS}

I. Ribeiro SM, Ajzen AS, Trindade JCS. Estudo comparativo dos métodos de ultrasso-nografia, tomografia computadorizada e ressonância magnética no estadiamento e invasão das estruturas adjacentes por tumores renais. Rev Assoc Med Bras 200 I; 47: 198-207.

2. Daniel WW, Hartman GW, Witten DM, Farrow GM, Kelalis PP. Calcified renal masses - A review of ten years experience at the Mayo Clinic. Radiology 1972;. 103:503-8.

3. Sniderman KW, Krieger JN, Seligson GR, Sos TA. The radiologic and clinical aspects of calcified hypernephroma. Radiology 1979; |3|:3|-5.

4. Weyman PJ, McClennan BL, Lee JKJ, Stanley RJ. CT of calcified renal masses. AJR Am J Roentgenol 1982; 138: 1095-9.

5. Siegel S. Nonparametric statistics. Tokyo: McGraw-Hill Book Company; 1956

6. Levine E. Malignant renal parenchymal tumors in adults. In: Pollack HM, editor. Clinical Urography. Philadelphia: WB Saunders; 1990. p. 1216-91.

7. Kass DA, Hricak H, Davidson AJ. Renal malignancies with normal excretory urograms. AJR Am J Roentgenol 1983; 141:731-4.

8. Holmberg G, Hietala SO, Ljungberg B. A comparison of radiologic methods in the diagnosis of renal mass lesions. Scand J Urol Nephrol 1988; 22: 187-96.
9. Warshauer DM, McCarthy SM, Street L, Bookbinder MJ, Glickman MG, Richter J, et al. Detection of renal masses: sensitivities and specificities of excretory urography, linear tomography, US, and CT. Radiology 1988; 169:363-5

10. Amendola MA, Bree RL, Pollack HM, Francis IR, Glazer GM, Jafri SZH, et al. Smal renal cell carcinomas: resolving a diagnostic dilemma. Radiology 1988; 166:637-41.

II. Sthephenson TF, lyengar S, Rashid HA. Comparison of computerized tomography and excretory urography in detection and evaluation of renal masses. J Urol 1984; 131: I I-3.

12. Fangliu $G$. Imaging techniques for the diagnosis of renal tumores. Proc CAMS and PUMC 1990; 5:75-8

13. Palko A, Kuhn E, Grexa E, Hertelendy A. Renal cell carcinoma: Value of imaging examinations in diagnosis and staging. Fortschr Röntgenstr 1990; 153:585-90.

14. Hartman DS, Davidson AJ, Davis CJJR, Goldman SM. Infiltrative renal lesions: CTSonographic - Pathologic correlation. AJRAm J Roentgenol 1988; | 50: 106 |-4.

15. Levine E, Huntrakoon M, Wetzel LH. Small renal neoplasm: clinical, pathologic, and imaging features. AJR Am J Roentgenol 1989; | 53:69-74

16. Cronam JJ, Zeman RK. Renal mass imaging: the internist's role. Am J Med 1986; 81: 1026-32.

17. Skinner DG, Colvin RB, Vermillion CD, Pfister RC, Leadbetter WF. Diagnosis and management of renal cell carcinoma. A clinical and pathologic study of 309 cases. Cancer 1971; 28: 1 165-77.

18. Rubinstein I. Tumor renal incidental: aspectos diagnósticos e terapêuticos [tese]. Rio de Janeiro: Universidade Federal do Rio de Janeiro; 1990.

19. McClennan BL, Deyoe LA. The imaging evaluation of renal cell carcinoma: Diagnosis and staging. Radiol Clin North Am 1994; 32:55-69.

20. Curry NS. Small renal masses (lesion smaller than $3 \mathrm{~cm}$ ): Imaging evaluation and management. AJRAm J Roentgenol 1995; 164:355-62.

21. Gatenby RA. Diagnostic evaluation of a renal mass. Semin Oncol 1983; 10:40 I-II.

22. Dunnick NR. Renal lesions: great strides in imaging. Radiology 1992; 1 82:305-6.

23. Balfe DM, McClennan BL, Stanley RJ, Weyman PJ, Sagel SS. Evaluation of renal masses considered indeterminate on computed tomography. Radiology 1982; I 42:42 I-8.

24. Bosniak MA. The current radiological approach to renal cysts. Radiology 1986; I 58: I- 10 .

25. Koga S, Nishikido M, Inuzuka S, Sakamoto I, Hayashi T. Hayashi K, et al. An avaluation of Bosniak's radiological classification of cystic renal masses. BJU Int 2000;86:607-9.
26. Elder DD, Orell LR, Sage MR, Sinclair GR, Marshall VR. The diagnosis and local staging of renal cancer - an appraisal. Aust N Z J Surg |984:54:219-2|

27. Coll DM, Uzzo RG, Herts BR, Davros WJ, Wirth SL, Novick AC. 3-Dimensional volume rendered computerized tomography for preoperative evaluation and intraoperative treatment of patients undergoing nephron sparing surgery. J Urol 1999; 16 1: 1097-102.

28. TakebayashiS, Hosaka M, Takase K, Kubota N, Kishida T, Matsubara S. Computerized tomography nephroscopy images of renal pelvic carcinoma. J Urol 1999; 162:315-8.

29. Levine E. Renal cell carcinoma: Clinical aspects, imaging diagnosis and staging. Semin Roentgenol 1995;30: 128-48

30. Zagoria RJ, Bechtold RE, Dyer RB. Staging of renal adenocarcinoma: role of varions imaging procedures. AJR Am | Roentgenol 1995; 164 : 367-70

31. Phillips TL, Chin FG, Palubinskas AJ. Calcification in renal masses: An eleven-year survey. Radiology 1963; 80:786-94.

32. Coleman BG, Arger PH, Mintz MC, Pollack HM, Banner MP. Hiperdense renal masses: A computed tomographia dilemma. AJR Am J Roentgenol 1984; | 43:29 |-4.

33. Novick AC, Streem S, Montie JE, Pontes JE, Siegel S, Montague DK, et al. Conservative surgery for renal cell carcinoma: A singlecenter experience with 100 patients. J Urol 1989;141:835-9

34. Black WC, Ling A. Is earlier diagnosis really better? The misleading effects of lead time and lengh biases. AJR Am J Roentgenol 1990; 155:625-30.

35. Smith SJ, Bosniak MA, Megibow AJ, Hulnick DH, Horii SC, Raghavendra BN. Renal cell carcinoma earlier discovery and increased detection. Radiology 1989; 170:699-703.

36. Kuijpers D, Jaspers R. Renal masses: Differential diagnosis with pulsed Doppler US. Radiology 1989; 170:59-60

37. Kier R, Taylor KJW, Feyock AL, Ramos IM. Renal masses: characterization with Doppler US. Radiology 1990; 176:703-7.

38. Van Campenhout I, Patriquin H. Malignant microvasculature in abdominal tumors in children: detection with Doppler US. Radiology 1992; 183:445-8.

Artigo recebido: 28/08/2003 Aceito para publicação: 26/02/2004 